\title{
Del Nido cardioplegia: A one stop shot for adult cardiac surgery?
}

\author{
Derrick Y. Tam, MD, and Stephen E. Fremes, MD, MSc
}

\footnotetext{
From the Division of Cardiac Surgery, Schulich Heart Centre, Department of Surgery, Sunnybrook Health Sciences Centre, University of Toronto, Toronto, Ontario, Canada.

Disclosures: Authors have nothing to disclose with regard to commercial support.

Received for publication Oct 13, 2017; accepted for publication Oct 24, 2017; available ahead of print Nov 29 , 2017.

Address for reprints: Stephen E. Fremes, MSc, MD, FRCSC, FACP, FACC, Schulich Heart Centre, Sunnybrook Health Sciences Centre, 2075 Bayview Ave, Room H4 05, Toronto, Ontario M4N 3M5, Canada (E-mail: Stephen.fremes@sunnybrook.ca).

J Thorac Cardiovasc Surg 2018;155:1019-20

$0022-5223 / \$ 36.00$

Copyright (c) 2017 by The American Association for Thoracic Surgery

https://doi.org/10.1016/j.jtcvs.2017.10.066
}

Although it was initially developed for congenital heart surgery, del Nido cardioplegia (DN) has recently gained widespread attention in adult cardiac surgery. ${ }^{1}$ Its purported benefit in pediatric surgery include its long duration of action with a single dose and its potential for improved myocardial protection through reduced energy consumption and scavenging of inflammatory substrates. These potential benefits have led DN to be evaluated further in adult cardiac surgery. Multiple studies have examined DN in various settings in adult cardiac surgical populations, from complex valve surgery to coronary artery bypass grafting for acute coronary syndrome..$^{2-7}$ All these studies, however, have been observational and retrospective in nature.

In this issue of the Journal, Ad and colleagues ${ }^{8}$ present their findings from a randomized clinical trial examining the efficacy and safety of DN versus whole blood cardioplegia in patients undergoing nonemergency isolated coronary artery bypass grafting (CABG), isolated valve surgery, and combined valve and $\mathrm{CABG}$ surgery. Patients were block randomized such that both baseline characteristics and procedural type were well balanced between the arms. In this study, the primary outcome was myocardial preservation, as assessed through 4 means: return to spontaneous rhythm, defibrillation requirement, inotropic support, and serial troponin values. Important secondary outcomes included mortality and morbidity, as defined by the Society of Thoracic Surgeons National Database.

Although it was initially designed as a noninferiority trial with a planned analysis of 250 patients per group, the study was stopped very early after an interim analysis showed superiority in one of the primary outcomes in the DN group. The trial enrolled a total of 89 patients between the arms. Given that an interim analysis took place and that there were four primary outcomes, a new $P$ value for superiority was calculated $(P<.001)$. As none of the 4 primary outcome variables approached the new statistical threshold, we can only conclude from this trial that DN is noninferior and not superior to blood cardioplegia. Interestingly, there

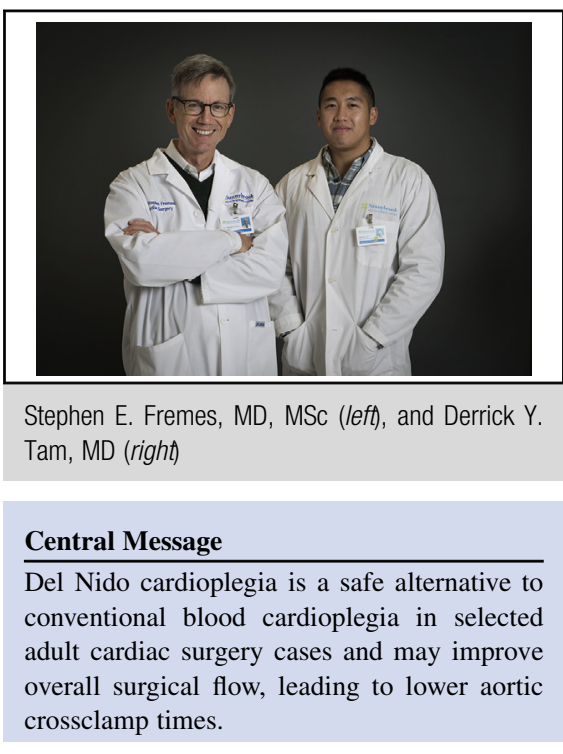

See Article page 1011.

was no difference in cardiopulmonary bypass time (97 vs 103 minutes; $P=.288$ ), although aortic crossclamp time was reduced (70 vs 83 minutes; $P=.018$ ) with DN relative to whole blood cardioplegia. These findings are relevant, because both cardiopulmonary bypass time and aortic crossclamp time have shown to be independent risk factors for postoperative death. . $^{9,10}$

Nonetheless, findings from this study must be interpreted in the context of some limitations. The surgical team was unblinded, and there was no standardization for the use of inotropic support; this represents a potential source of bias. Furthermore, the clinical significance of the surrogate outcomes used in this study, such as the return of spontaneous rhythm or the need for defibrillation, remains unclear. Troponin values continued to rise in the control group, such that a peak could not be demonstrated. That said, the prognostic significance of small rises in postoperative troponin levels after cardiac surgery in the absence of electrocardiographic and echocardiographic findings is uncertain and controversial. ${ }^{11}$ The study findings are only generalizable to patients in stable condition who required either isolated $\mathrm{CABG}$, isolated single valve, or single valve and $\mathrm{CABG}$. The investigators specifically excluded high-risk patients, including those requiring preoperative inotropic support and preoperative mechanical circulatory support. Most of the cases were elective; the safety of single-shot cardioplegia for $\mathrm{CABG}$ after acute coronary syndrome could be 
affected by the compromised coronary circulation. In a propensity matched study of 40 patient pairs undergoing highrisk CABG after an acute myocardial infarction, no differences in early mortality, inotropy requirement, or intraaortic balloon pump requirement were noted. ${ }^{6}$ Furthermore, the results reported by $\mathrm{Ad}$ and colleagues ${ }^{8}$ were derived from a single center of excellence, with an institutionspecific protocol used for the delivery and composition of both conventional and DN cardioplegia that may be different from that in other centers.

The most important point to stress is that this trial was initially designed to assess noninferiority between DN and whole blood cardioplegia but was stopped early because of the benefits seen in the DN group. The decision to end clinical trials prematurely is difficult and remains controversial. ${ }^{12-14}$ Patient protection is paramount in trials, and studies are stopped prematurely, in general, for excess harm rather than benefit. Still, a meta-analysis and metaregression of early truncated clinical trials suggest that these trials often overestimate the true effect size relative to nontruncated studies. ${ }^{15}$ In this case, Ad and colleagues ${ }^{8}$ justified the early termination of this trial, because one of their primary outcomes, spontaneous return of rhythm, was found to be not only noninferior but superior at the interim analysis. Other important outcomes, however, such as inotropic requirements, cardiopulmonary bypass time, crossclamp time, and the composite of Society of Thoracic Surgeons-defined complications trended lower in the DN group but were not statistically significantly different at the revised $\alpha$ threshold for superiority. The continuation of the trial to a higher recruitment level might have provided the power necessary to detect important differences on clinically relevant outcomes. Also, a larger sample size might have allowed for some subgroup analyses. Overall, this article reaffirms and highlights the challenge in designing and completing adequately powered studies in cardiac surgery for clinically relevant outcomes that reflect myocardial protection. Recent large clinical trials in cardiac surgery that examined the rate of perioperative myocardial infarction or low cardiac output syndrome have enrolled totals of 800 to 4000 patients. ${ }^{16-18}$

Again, Ad and colleagues ${ }^{8}$ are to be commended for conducting a relevant study and shedding light on this important topic critical to performing safe cardiac surgery. DN may be particularly advantageous in mitral valve operations because the valvular correction does not need to be interrupted by frequent readministration of cardioplegia, thereby improving surgical workflow. Although multiple strategies of protection are sufficient for most cardiac operations, there remains an unmet need for a simple approach that can reliably preserve the myocardium for very lengthy, complex procedures. The findings from this randomized, controlled trial ${ }^{8}$ confirm those of a recently published meta-analysis of observational studies; the aortic cross- clamp time was lower with DN, and there were no differences in mortality, cardiac enzyme release, or the need for inotropic support. ${ }^{19}$ Nonetheless, there remains a need for further investigation in the form of a much larger multicenter clinical trial to prove the generalizability of these results. Although DN may not be the one-stop shot for all adult cardiac surgery, it has certainty proved its benefit for coronary artery bypass grafting and single-valve surgery in this small randomized, controlled trial.

\section{References}

1. Matte GS, del Nido PJ. History and use of del Nido cardioplegia solution at Boston Children's Hospital. J Extra Corpor Technol. 2012;44:98-103.

2. Ziazadeh D, Mater R, Himelhoch B, Borgman A, Parker JL, Willekes CL, et al. Single-dose del Nido cardioplegia in minimally invasive aortic valve surgery Semin Thorac Cardiovasc Surg. November 2, 2017 [Epub ahead of print].

3. Guajardo Salinas GE, Nutt R, Rodriguez-Araujo G. Del Nido cardioplegia in low risk adults undergoing first time coronary artery bypass surgery. Perfusion. 2017;32:68-73.

4. Vistarini N, Laliberté E, Beauchamp P, Bouhout I, Lamarche Y, Cartier R, et al. Del Nido cardioplegia in the setting of minimally invasive aortic valve surgery. Perfusion. 2017;32:112-7.

5. Timek T, Willekes C, Hulme O, Himelhoch B, Nadeau D, Borgman A, et al. Propensity matched analysis of del Nido cardioplegia in adult coronary artery bypass grafting: initial experience with 100 consecutive patients. Ann Thorac Surg. 2016;101:2237-41.

6. Yerebakan H, Sorabella RA, Najjar M, Castillero E, Mongero L, Beck J, et al. Del Nido cardioplegia can be safely administered in high-risk coronary artery bypass grafting surgery after acute myocardial infarction: a propensity matched comparison. J Cardiothorac Surg. 2014;9:141.

7. Ota T, Yerebakan H, Neely RC, Mongero L, George I, Takayama H, et al. Shortterm outcomes in adult cardiac surgery in the use of del Nido cardioplegia solution. Perfusion. 2016;31:27-33.

8. Ad N, Holmes SD, Massimiano PS, Rongione AJ, Fornaresio LM, Fitzgerald D. The use of del Nido cardioplegia in adult cardiac surgery: A prospective randomized trial. J Thorac Cardiovasc Surg. 2018;155:1011-8.

9. Salis S, Mazzanti VV, Merli G, Salvi L, Tedesco CC, Veglia F, et al. Cardiopulmonary bypass duration is an independent predictor of morbidity and mortality after cardiac surgery. J Cardiothorac Vasc Anesth. 2008;22:814-22.

10. Nissinen J, Biancari F, Wistbacka JO, Peltola T, Loponen P, Tarkiainen P, et al. Safe time limits of aortic cross-clamping and cardiopulmonary bypass in adult cardiac surgery. Perfusion. 2009;24:297-305.

11. Wang TK, Stewart RA, Ramanathan T, Kang N, Gamble G, White HD. Diagnosis of MI after CABG with high-sensitivity troponin T and new ECG or echocardiogram changes: relationship with mortality and validation of the universal definition of MI. Eur Heart J Acute Cardiovasc Care. 2013;2:323-33.

12. Ellenberg SS, DeMets DL, Fleming TR. Bias and trials stopped early for benefit JAMA. 2010;304:158. author reply 158-9.

13. Goodman S, Berry D, Wittes J. Bias and trials stopped early for benefit. JAMA 2010;304:157. author reply 158-9.

14. Bassler D, Montori VM, Briel M, Glasziou P, Walter SD, Ramsay T, et al. Reflec tions on meta-analyses involving trials stopped early for benefit: is there a problem and if so, what is it? Stat Methods Med Res. 2013;22:159-68.

15. Bassler D, Briel M, Montori VM, Lane M, Glasziou P, Zhou Q, et al. Stopping randomized trials early for benefit and estimation of treatment effects: systematic review and meta-regression analysis. JAMA. 2010;303:1180-7.

16. Mehta RH, Leimberger JD, van Diepen S, Meza J, Wang A, Jankowich R, et al. Levosimendan in patients with left ventricular dysfunction undergoing cardiac surgery. N Engl J Med. 2017;376:2032-42.

17. Newman MF, Ferguson TB, White JA, Ambrosio G, Koglin J, Nussmeier NA, et al. Effect of adenosine-regulating agent acadesine on morbidity and mortality associated with coronary artery bypass grafting: the RED-CABG randomized controlled trial. JAMA. 2012;308:157-64.

18. Lamy A, Devereaux PJ, Prabhakaran D, Taggart DP, Hu S, Straka Z, et al. Fiveyear outcomes after off-pump or on-pump coronary-artery bypass grafting. $N$ Engl J Med. 2016;375:2359-68.

19. Li Y, Lin H, Zhao Y, Li Z, Liu D, Wu X, et al. Del Nido cardioplegia for myocardial protection in adult cardiac surgery: a systematic review and meta-analysis. ASAIO J. August 31, 2017 [Epub ahead of print]. 